See discussions, stats, and author profiles for this publication at: https://www.researchgate.net/publication/334199748

\title{
Risk factors and comorbidity of ICD-11 PTSD and complex PTSD: Findings from a trauma-exposed population based sample of adults in the United Kingdom
}

Article in Depression and Anxiety · July 2019

DOI: 10.1002/da.22934

CITATIONS

25

7 authors, including:

Thanos Karatzias

Edinburgh Napier University

181 PUBLICATIONS 2,864 CITATIONS

SEE PROFILE

Aoife Bradley

Newcastle University

9 PUBLICATIONS 136 CITATIONS

SEE PROFILE
READS

908

8 Philip Hyland 216 PUBLICATIONS 2,950 CITATIONS

SEE PROFILE

Marylene Cloitre

National Center for PTSD

219 PUBLICATIONS 12,615 CITATIONS

SEE PROFILE

Some of the authors of this publication are also working on these related projects:

Paradoxes and parallels: exploring the health implications of country vulnerability View project

CONTEXT (The COllaborative Network for Training and EXcellence in psychoTraumatology) View project 


\title{
Risk factors and comorbidity of ICD-11 PTSD and complex PTSD: Findings from a trauma-exposed population based sample of adults in the United Kingdom
}

\author{
Thanos Karatzias $^{1,2}$ (1) | Philip Hyland ${ }^{3,4}$ | Aoife Bradley ${ }^{1}$ | Marylène Cloitre ${ }^{5,6}$ | \\ Neil P. Roberts ${ }^{7,8}$ | Jonathan I. Bisson ${ }^{8}$ Mark Shevlin ${ }^{9}$
}

${ }^{1}$ School of Health \& Social Care, Edinburgh Napier University, Edinburgh, UK

${ }^{2} \mathrm{NHS}$ Lothian, Rivers Centre for Traumatic Stress, Edinburgh, UK

${ }^{3}$ Department of Psychology, Maynooth University, Kildare, Ireland

${ }^{4}$ Centre for Global Health, Trinity College Dublin, Dublin, Ireland

${ }^{5}$ National Center for PTSD Dissemination and Training Division, VA Palo Alto Health Care System, Palo Alto, California

${ }^{6}$ Department of Psychiatry and Behavioural Sciences, Stanford University, Stanford, California

${ }^{7}$ Psychology and Psychological Therapies Directorate, Cardiff \& Vale University Health Board, Cardiff, UK

${ }^{8}$ Division of Psychological Medicine \& Clinical Neurosciences, School of Medicine, Cardiff University, Cardiff, UK

'Ulster University, School of Psychology, Derry, Northern Ireland

\section{Correspondence}

Thanos Karatzias, Edinburgh Napier University, Sighthill Campus, Sighthill Court, Edinburgh EH11 4BN, Scotland, UK. Email. t.karatzias@napier.ac.uk

\begin{abstract}
Background: Following the recently published 11th version of the WHO International Classification of Diseases (ICD-11), we sought to examine the risk factors and comorbidities associated with posttraumatic stress disorder (PTSD) and complex PTSD (CPTSD).

Method: Cross-sectional and retrospective design. The sample consisted of 1,051 trauma-exposed participants from a nationally representative panel of the UK adult population.

Results: A total of $5.3 \%$ (95\% confidence interval $[\mathrm{Cl}]=4.0-6.7 \%)$ met the diagnostic criteria for PTSD and $12.9 \%(95 \% \mathrm{Cl}=10.9-15.0 \%)$ for CPTSD. Diagnosis of PTSD was independently associated with being female, being in a relationship, and the recency of traumatic exposure. CPTSD was independently associated with younger age, interpersonal trauma in childhood, and interpersonal trauma in adulthood. Growing up in an urban environment was associated with the diagnosis of PTSD and CPTSD. High rates of physical and mental health comorbidity were observed for PTSD and CPTSD. Those with CPTSD were more likely to endorse symptoms reflecting major depressive disorder (odds ratio $[O R]=21.85,95 \mathrm{Cl}=12.51-38.04$ ) and generalized anxiety disorder $(O R=24.63,95 \mathrm{Cl}=14.77-41.07)$. Presence of PTSD (OR = 3.13, $95 \mathrm{Cl}=1.81-5.41)$ and CPTSD (OR=3.43, $95 \mathrm{Cl}=2.37-4.70$ ) increased the likelihood of suicidality by more than three times. Nearly half the participants with PTSD and CPTSD reported the presence of a chronic illness.

Conclusions: CPTSD is a more common, comorbid, debilitating condition compared to PTSD. Further research is now required to identify effective interventions for its treatment.
\end{abstract}

KEYWORDS

comorbidities, ICD-11 CPTSD, ICD-11 PTSD, risk factors 


\section{1 | INTRODUCTION}

In 2018, the World Health Organization published the 11th version of the International Classification of Diseases (ICD-11); the official diagnostic system used worldwide (WHO, 2018). Substantial revisions were made to the trauma-related diagnoses in ICD-11 that are located within the parent category of "Disorders Specifically Associated with Stress." The symptom profile and diagnostic requirements for posttraumatic stress disorder (PTSD) were narrowed relative to the ICD-10 and the fifth edition of the Diagnostic and Statistical Manual (DSM-5: American Psychiatric Association, 2013), and complex PTSD (CPTSD) was introduced to the diagnostic nomenclature for the first time (see Table 1; Maercker et al., 2013). A multinational field survey found that clinicians demonstrated accuracy in differential diagnoses between PTSD and CPTSD formulations (Keeley et al., 2016), and a review of the extant research indicated support for the construct validity of PTSD and CPTSD (Brewin et al., 2017).

CPTSD has been shown to occur more frequently after exposure to traumatic events that are of an interpersonal nature, that are difficult or impossible to escape from, and particularly when occurring during early development (e.g., childhood sexual abuse, torture, captivity; see Karatzias, Cloitre, et al., 2018). CPTSD is also a more impairing condition than PTSD (Karatzias et al., 2017) and may require enhanced interventions, which are quantitatively and qualitatively different to those currently offered for PTSD (Karatzias, Shevlin, et al., 2018). Little is currently known about the risk factors that differentiate PTSD and CPTSD after traumatic exposure, or, how frequently other mental and physical health disorders co-

TABLE 1 Symptom and diagnostic profile for ICD-11 PTSD and CPTSD

\begin{tabular}{|c|c|}
\hline PTSD & CPTSD \\
\hline Traumatic exposure (required) & $\begin{array}{l}\text { All PTSD diagnostic requirements } \\
\text { necessary and disturbances in } \\
\text { self-organization (DSO) }\end{array}$ \\
\hline $\begin{array}{l}\text { Re-experiencing in the here } \\
\text { and now ( } 1 \text { of } 2 \text { required) }\end{array}$ & $\begin{array}{l}\text { Affective dysregulation (1 of } 2 \\
\text { required) }\end{array}$ \\
\hline 1. Upsetting dreams & 7. Emotional reactivity \\
\hline 2. Flashbacks & 8. Emotional numbing \\
\hline $\begin{array}{l}\text { Avoidance of traumatic } \\
\text { reminders ( } 1 \text { of } 2 \text { required) }\end{array}$ & $\begin{array}{l}\text { Negative self-concept (1 of } 2 \\
\text { required) }\end{array}$ \\
\hline 3. Internal reminders & 9. Failure \\
\hline 4. External reminders & 10. Worthless \\
\hline $\begin{array}{l}\text { Sense of threat (1 of } 2 \\
\text { required) }\end{array}$ & $\begin{array}{l}\text { Disturbances in relationships ( } 1 \\
\text { of } 2 \text { required) }\end{array}$ \\
\hline 5. Vigilance & 11. Cut-off from people \\
\hline 6. Hyperarousal & 12. Hard to stay close to others \\
\hline $\begin{array}{l}\text { Functional impairment } \\
\text { associated with these } \\
\text { symptoms (required) }\end{array}$ & $\begin{array}{l}\text { Functional impairment associated } \\
\text { with these symptoms (required) }\end{array}$ \\
\hline
\end{tabular}

Abbreviations: CPTSD, complex posttraumatic stress disorder; PTSD, posttraumatic stress disorder. occur with PTSD and CPTSD. Emerging evidence, primarily drawn from clinical samples, suggests that childhood sexual abuse, negative trauma-related cognitions, distress intolerance, and unemployment status are associated with an increased risk of CPTSD (Hyland et al., 2017; Hyland, Shevlin, Fyvie, \& Karatzias, 2018). Furthermore, CPTSD is more strongly associated with symptoms of depression, anxiety, borderline personality disorder, and suicidality than PTSD (Hyland et al., 2018). Identifying risk factors and comorbidities associated with these disorders has important implications for diagnosis and subsequent treatment, as well as for the prevention and early intervention. If clinicians know who is more likely to be adversely affected by a particular disorder following traumatic exposure, they can monitor individuals with a view to providing interventions before their problems become chronic. Especially in the case of CPTSD, an understanding of the risk factors will contribute to the development of theoretical models to explain its onset and course, which could ultimately lead to more focused interventions and better treatment outcomes.

With this in mind, the current study was undertaken to (a) identify demographic (gender, age, urbanicity, history of emigration, relationship status, number of children, employment status, and education status) and trauma-related (time passed since traumatic exposure, childhood noninterpersonal trauma, childhood interpersonal trauma, adulthood noninterpersonal trauma, and adulthood interpersonal trauma) risk factors associated with PTSD and CPTSD diagnosis; and (b) determine the comorbidity rates for PTSD and CPTSD with major depressive disorder (MDD), generalized anxiety disorder (GAD), alcohol use disorder (AUD), suicidality, and the presence of a chronic illness. Based on the existing literature of the risk factors for ICD-11 PTSD and CPTSD, as well as the wider trauma literature, we expected that PTSD would be associated with being female (Tolin \& Foa, 2006) and that CPTSD would be associated with exposure to an increased number of interpersonal trauma types during childhood (Hyland et al., 2017). Although not yet examined in relation to ICD-11 PTSD and CPTSD, urban residence has been shown to increase the risk for multiple psychiatric disorders including mood and anxiety disorders independent of other covariates (Peen, Schoevers, Beekam, \& Dekker, 2010), therefore, we expected that growing up in an urban area would be associated with an increased risk for both PTSD and CPTSD. Finally, based on data from clinical (Hyland et al., 2018) and internally displaced (Shevlin et al., 2018) samples, we expected that PTSD and CPTSD would be highly comorbid with the other psychiatric disorders measured in this study.

\section{2 | METHODS}

\section{1 | Participants and procedures}

A trauma-exposed adult sample of the United Kingdom (UK) population was used in the current study. Sample participants were drawn from an existing online research panel that was representative of the UK adult population. Panel members were randomly recruited through probability-based sampling. Inclusion criteria for the current 
sample were that respondents were (a) born in the UK, (b) aged 18 years or older at the time of the survey, and (c) screened positive for at least one traumatic event in their lifetime (assessed using the Life Events Checklist [LEC], described below). Ethical approval was granted by the Research Ethics Committee of the institution to which the second author was affiliated at the time of the survey. No inducements or incentives were offered for participation. In total, 2,653 panel members were contacted, and 1,051 people qualified for inclusion on the basis of meeting the inclusion criteria (selection rate $=39.6 \%$ ).

The mean age of the sample was 47.18 years $(S D=15.00$, range $=18-90$ years $)$, and $68.4 \%(n=719)$ of participants were female. The majority of respondents indicated that they did not grow up in an urban area $(54.7 \%, n=574)$, had not emigrated in their lifetime $(82.2 \%$, $n=864)$, were currently in a committed relationship $(70.4 \%, n=740)$, did not have any children under the age of 16 years $(67.5 \%, n=709)$, were in full- or part-time employment $(58.5 \%, n=615)$, and had completed a college or university education $(62.7 \%, n=659)$.

\section{2 | Measures}

\subsection{1 | Traumatic exposure}

A revised version of the LEC for DSM-5 (Weathers et al., 2013) was used to assess for childhood ("before the age of 18") and adulthood ("at or after the age of 18 ") exposure to 16 different traumatic events. Participants indicated on a "Yes" (1) or "No" (0) basis if they had directly experienced each traumatic event during both developmental periods. Following Ehring and Quack's (2010) approach, we calculated summed scores for noninterpersonal trauma (natural disaster, fire or explosion, transportation accident, serious accident at work or home or during recreational activity, exposure to toxic substance, life-threatening illness or injury, severe human suffering, sudden and violent death, and sudden and unexpected death of someone close to you) and interpersonal trauma (physical assault, assault with a weapon, sexual assault, other unwanted or uncomfortable sexual experiences, combat or exposure to a war-zone, captivity, and serious injury and/or harm and/or death you caused to someone else) in childhood and adulthood. Scores for noninterpersonal trauma (in childhood and in adulthood) ranged from 0 to 9 , and scores for interpersonal trauma (in childhood and in adulthood) ranged from 0 to 7 .

\subsection{2 | ICD-11 PTSD and CPTSD}

The International Trauma Questionnaire (ITQ: Cloitre et al., 2018) is a self-report measure of ICD-11 PTSD and CPTSD. The ITQ assesses the respondent's most distressing traumatic event and the time passed since the trauma occurred (response options: $<6$ months ago 6-12 months ago, $1-5$ years ago, 5-10 years ago, $10-20$ years ago, and $>20$ years ago). The ITQ contains 12 items measuring the six PTSD $(\alpha=.91)$ and six disturbances in self-organization (DSO) symptoms $(\alpha=.92)$. There are three items measuring functional impairment (in the domains of social-life, work-life, and other important areas of life) associated with both sets of symptoms.
Individuals respond to the PTSD items in terms of how much they have been bothered by each symptom over the past month, and respond to the DSO items in terms of how they typically feel, think about themselves, and relate to others. All items are measured using a five-point Likert scale ranging from 0 ("Not at all") to 4 ("Extremely"). Diagnostic requirements are presented in Table 1, and a symptom was considered present based on a score of $\geq 2$ ("Moderately"). Importantly, the ICD-11 diagnostic rules only permit a diagnosis of PTSD or CPTSD, not both. The psychometric properties of the ITQ, and the diagnostic rates of PTSD and CPTSD were demonstrated in a prior study based on this exact sample (Cloitre et al., 2018). The diagnostic rates are presented below in the results section.

\subsection{3 | Major depressive disorder}

The Patient Health Questionnaire-9 (PHQ-9; Kroenke, Spitzer, \& Williams, 2001) is a nine-item, self-report measure of MDD that aligns to the diagnostic criteria of the DSM-5 (American Psychiatric Association, 2013). Individuals are instructed to respond to each item in terms of how much they have been bothered by that symptom over the past 2 weeks using a four-point Likert scale ranging from 0 ("Not at all") to 3 ("Nearly every day"). The PHQ-9 has demonstrated strong psychometric properties (Manea, Gilbody, \& McMillan, 2015) and the internal reliability among the current sample was excellent $(\alpha=.94)$. Scores range from 0 to 27 and scores $\geq 10$ are indicative of a diagnosis of MDD (Kroenke et al., 2009).

\subsection{4 | Generalized anxiety disorder}

The generalized anxiety disorder seven-item scale (GAD-7; Spitzer, Kroenke, Williams \& Löwe, 2006) is a seven-item, self-report measure of GAD. Individuals are instructed to respond to each item in terms of how much they have been bothered by each symptom over the past 2 weeks using a four-point Likert scale ranging from 0 ("Not at all") to 3 ("Nearly every day"). The GAD-7 has demonstrated good psychometric properties (Kertz, Bigda-Peyton, \& Bjorgvinsson, 2013) and the internal reliability among the current sample was excellent $(\alpha=.95)$. Scores range from 0 to 21 and scores $\geq 10$ are indicative of a diagnosis of GAD (Spitzer et al., 2006).

\subsection{5 | Alcohol use disorder}

The presence of an AUD was measured using the AUDIT-C, a brief self-report measure comprised of the first three questions of the Alcohol Use Disorders Identification Test (Saunders, Aasland, Babor, \& de la Fuente, 1993). The clinical utility of the AUDIT-C has been demonstrated in multiple samples including the general population (Nayak, Bond, Cherpitel, Patel, \& Greenfield, 2009), military veterans (Bradley et al., 2003), and hospitalized patients (Kelly, Donovan, Chung, Bukstein, \& Cornelius, 2009). Scores on the AUDIT-C range from 0 to 12 , and based on a nationally representative sample of 
adults from the United States, scores $\geq 4$ effectively capture a DSM-5 diagnosis of AUD (Dawson, Smith, Saha, Rubinsky, \& Grant, 2012).

\subsection{6 | Suicidality/Self-harm}

Suicidality was measured using two items taken from a self-report measure of borderline personality disorder symptoms. These questions asked respondents: "Have you tried to hurt or kill yourself or threatened to do so?" and "Have you ever cut, burned, or scratched yourself on purpose?" These items were responded to using a "Yes" (1) or "No" (0) response format. A person was deemed to screen positive for lifetime suicidality if they answered "Yes" to either question.

\subsection{7 | Chronic illness}

The presence of a chronic illness was assessed using the first item of the Charlson comorbidity index (Charlson, Pompei, Ales, \& MacKenzie, 1987). This item asks the respondent "Do you suffer from any chronic illness?" using a "Yes" (1) or "No" (0) response scale. Respondents are subsequently asked to indicate the specific type of chronic illness they have been diagnosed with.

\section{3 | Data analysis}

Hierarchical binary logistic regression analysis was used to examine the associations between each risk factor and meeting diagnostic criteria for PTSD and CPTSD, respectively. Eight demographic variables were entered into the model at Step 1 and these were sex $(0=$ Male, $1=$ Female), age (measured years), having grown up in an urban area $(0=\mathrm{No}, 1=\mathrm{Yes})$, history of emigration $(0=\mathrm{No}, 1=\mathrm{Yes})$, relationship status $(0=$ Not in a committed relationship, $1=\ln$ a committed relationship), number of children under the age of 16 , employment status ( $0=$ Employed, $1=$ Unemployed), and attendance of college/ university $(0=$ No, $1=$ Yes $)$. Five trauma-related variables were entered into the model in Step 2 and these included the time passed since trauma (1: <6 months ago, 2: 6-12 months ago, 3: 1-5 years ago, 4: 5-10 years ago, 5: 10-20 years ago, 6: >20 years ago), childhood noninterpersonal trauma, childhood interpersonal trauma, adulthood noninterpersonal trauma, and adulthood interpersonal trauma. The comorbidity rates for PTSD and CPTSD with MDD, GAD, AUD, suicidality, and chronic illness were evaluated using the Pearson $\chi^{2}$ tests. There was very little missing data present $(0.19 \%)$ and the default listwise deletion method in SPSS was used in all analyses.

\section{3 | RESULTS}

\subsection{Life events and common mental health problems}

The most common traumatic event in childhood was physical assault (32.4\%, $n=340$ ) and the most common traumatic event in adulthood was the sudden and unexpected death of a loved one $(47.4 \%$, $n=498$ ). The sudden and unexpected death of a loved one was most commonly reported as the "most distressing traumatic event" $(29.4 \%$, $n=309$ ). With respect to the time passed since the trauma, the most common response was "more than 20 years ago" $(40.1 \%, n=421)$. The mean number of childhood noninterpersonal trauma types was $0.84(S D=1.31$, range $=0-9)$ and the mean number of childhood interpersonal trauma types was also $0.84(S D=1.20$, range $=0-7)$. The mean number of adulthood noninterpersonal trauma types was $1.43(S D=1.49$, range $=0-9)$, and the mean number of adulthood interpersonal trauma types was $0.82(S D=1.27$, range $=0-7)$. Bivariate correlations between the different types of trauma were all statistically significant $(p<.001)$ and ranged from 0.26 (between childhood interpersonal trauma and adulthood noninterpersonal trauma) to 0.52 (between childhood interpersonal trauma and childhood noninterpersonal trauma).

As reported in Cloitre et al. (2018), the PTSD diagnostic criteria were met by 56 respondents $(5.3 \%[95 \% \mathrm{Cl}=4.0-6.7 \%])$ and the CPTSD diagnostic criteria were met by 136 respondents (12.9\% [95\% $\mathrm{Cl}=10.9-15.0 \%])$. Furthermore, based on the recommended cut-off scores of >10 for the PHQ-9 and GAD-7, respectively, 368 respondents (35\% [95\% Cl $=32.1-37.9 \%]$ ) had a probable MDD diagnosis and 300 (28.5\% [95\% Cl=25.8-31.3\%]) had a probable GAD diagnosis. In addition, $353(33.6 \%[95 \% \mathrm{Cl}=30.7-36.4 \%])$ participants had a probable AUD diagnosis based on the recommended cut-off score of $>4$ for the AUDIT-C, 329 (31.3\% [95\% Cl=28.5-34.1\%]) reported a history of suicidality, and $322(30.6 \%$ [95\% Cl $=27.8-33.4 \%])$ reported having been diagnosed with a chronic illness.

\section{2 | Risk factors for PTSD and CPTSD}

The results of the two binary logistic regression analyses for PTSD and CPTSD are presented in Table 2 . In the case of meeting diagnostic criteria for PTSD, Step 1 of the model (which included the demographic variables) was statistically significant $\left.\chi^{2}(8)=23.03, p=.003\right)$, and growing up in an urban area $(\mathrm{OR}=2.02)$ and being in a committed relationship $(O R=2.30)$ were significantly associated with PTSD. The trauma variables were entered at Step 2 and did not significantly improve the model $\left(\chi^{2}(5)=5.68, p=.339\right)$. The full model was statistically significant $\left(\chi^{2}(13)=28.71, p=.007\right)$ and, when adjusting for all demographic and trauma factors, four variables were significantly associated with a diagnosis of PTSD: being female $(O R=2.08)$, having grown up in an urban area (OR $=2.05)$, being in a committed relationship $(O R=2.30)$, and less time having passed since trauma $(O R=.81)$.

In the case of meeting diagnostic criteria for CPTSD, Step 1 of the model was statistically significant $\left.\chi^{2}(8)=65.52, p<.001\right)$, and age $(O R=.96)$, growing up in an urban area $(O R=1.96)$, and having emigrated $(O R=1.62)$ were significantly associated with CPTSD. The inclusion of the trauma variables at Step 2 significantly improved the model $\left(\chi^{2}(5)=67.70, p<.001\right)$, and the model as a whole was significant: $\left.\chi^{2}(13)=133.25, p<.001\right)$. When adjusting for all demographic and trauma factors, four variables were significantly associated with a diagnosis of CPTSD: younger age $(O R=.97)$, growing up in an urban area $(O R=1.72)$, childhood interpersonal trauma $(O R=1.52)$, and adulthood interpersonal trauma $(O R=1.20)$. 
TABLE 2 Hierarchical binary logistic regression models for PTSD and CPTSD diagnosis

\begin{tabular}{|c|c|c|}
\hline & ICD-11 PTSD & ICD-11 CPTSD \\
\hline & OR $(95 \% \mathrm{Cl})$ & OR $(95 \% \mathrm{Cl})$ \\
\hline \multicolumn{3}{|l|}{ Step 1} \\
\hline Age & $0.99(0.97,1.01)$ & $0.96(0.94,0.97)^{* * *}$ \\
\hline Grew up in an urban area & $2.02(1.15,3.58)^{*}$ & $1.96(1.34,2.88)^{* *}$ \\
\hline In a relationship & $2.30(1.05,5.02)^{*}$ & $0.92(0.60,1.42)$ \\
\hline Number of children & $1.14(0.87,1.49)$ & $1.07(0.88,1.29)$ \\
\hline Unemployed & $0.98(0.55,1.74)$ & $1.37(0.93,2.02)$ \\
\hline University education & $1.17(0.64,2.15)$ & $0.79(0.53,1.17)$ \\
\hline Grew up in an urban area & $2.05(1.15,3.64)^{*}$ & $1.72(1.15,2.58)^{* *}$ \\
\hline History of emigration & $1.16(0.56,2.40)$ & $1.02(0.61,1.70)$ \\
\hline In a relationship & $2.30(1.05,5.03)^{*}$ & $0.93(0.60,1.45)$ \\
\hline Number of children & $1.12(0.85,1.48)$ & $0.92(0.74,1.14)$ \\
\hline Unemployed & $0.98(0.55,1.77)$ & $1.39(0.92,2.10)$ \\
\hline University education & $1.21(0.65,2.23)$ & $0.94(0.61,1.44)$ \\
\hline Time since trauma & $0.81(0.66,1.00)^{*}$ & $0.92(0.79,1.07)$ \\
\hline Childhood noninterpersonal trauma & $0.88(0.67,1.15)$ & $1.03(0.86,1.22)$ \\
\hline Childhood interpersonal trauma & $1.04(0.78,1.39)$ & $1.52(1.27,1.83)^{* * *}$ \\
\hline
\end{tabular}

Note: $n=1049$

Abbreviations: $\mathrm{Cl}$, confidence interval; CPTSD, complex posttraumatic stress disorder; OR, odds ratio; PTSD, posttraumatic stress disorder.

${ }^{*} p<.05$.

$*^{* *} p<.01$

${ }^{* * *} p<.001$.

\section{3 | ICD-11 PTSD and CPTSD comorbidities}

The comorbidities for PTSD ranged from a low of $30.4 \%$ with GAD to a high of $60.0 \%$ with AUD (see Table 3). Meeting criteria for PTSD was significantly (all $p<.05$ ) associated with an increased likelihood of having a probable MDD diagnosis $(O R=1.79)$, a chronic illness
$(O R=1.90)$, an AUD $(O R=2.04)$, and a history of suicidality $(O R=$ 3.13). The comorbidities for CPTSD ranged from a low of $45.6 \%$ with chronic illness to $89.0 \%$ with MDD. Meeting criteria for CPTSD significantly increased the likelihood of having every other condition (all $p<.01$ ) including being approximately 25 times more likely to have a probable MDD diagnosis and being 22 times more likely to

TABLE 3 Proportion of those with PTSD and CPTSD meeting probable diagnosis for other disorders

\begin{tabular}{|c|c|c|c|c|c|}
\hline & $\%$ with MDD & $\%$ with GAD & $\%$ with AUD & $\%$ with suicidality & $\%$ with chronic illness \\
\hline & OR $(95 \% \mathrm{Cl})$ & OR $(95 \% \mathrm{Cl})$ & OR $(95 \% \mathrm{Cl})$ & OR $(95 \% \mathrm{Cl})$ & OR $(95 \% \mathrm{Cl})$ \\
\hline PTSD & 48.2 & 30.4 & 60.0 & 57.1 & 44.6 \\
\hline \multirow[t]{2}{*}{ CPTSD } & 89.0 & 86.0 & 58.8 & 56.6 & 45.6 \\
\hline & $21.82(12.51-38.04)^{* * *}$ & $24.63(14.77-41.07)^{* * *}$ & $2.07(1.36-3.15)^{* *}$ & $3.43(2.37-4.70)^{* * *}$ & $2.11(1.46-3.05)^{* * *}$ \\
\hline
\end{tabular}

Abbreviations: AUD, alcohol use disorder; $\mathrm{Cl}$, confidence interval; CPTSD, complex posttraumatic stress disorder; GAD, generalized anxiety disorder; MDD, major depressive disorder; OR, odds ratio; PTSD, posttraumatic stress disorder.

${ }^{*} p<.05$.

${ }^{* *} p<.01$.

${ }^{* * *} p<.001$. 
have a probable GAD diagnosis. The associations between CPTSD and AUD, suicidality, and chronic illness, respectively, were of a similar magnitude to those observed for PTSD.

\section{4 | DISCUSSION}

\section{1 | Main findings}

Our results showed that physical abuse and the unexpected death of a loved one were the most common traumatic events during childhood and adulthood, respectively. We also found that PTSD was independently associated with being female, being in a committed relationship, and less time having passed since traumatic exposure. In contrast, CPTSD was independently associated with younger age, having experienced a higher number of different childhood interpersonal traumas, and having experienced a higher number of different adulthood interpersonal traumas. A shared risk factor associated with PTSD and CPTSD was growing up in an urban environment. High rates of comorbidity were observed for PTSD and CPTSD, however, in the cases of MDD and GAD, CPTSD was substantially more strongly associated with these disorders than was PTSD. Presence of PTSD and CPTSD increased the likelihood of suicidality by more than three times, and an AUD and a chronic illness by approximately two times.

\section{2 | Comparison with other studies}

In this trauma-exposed community sample of the UK population, we found that CPTSD was a more common diagnosis than PTSD. This is in contrast to findings from a nationally representative sample of the Israeli population that reported higher rates of PTSD (9.0\%) than CPTSD (2.6\%) (Ben-Ezra et al., 2018), and findings from a nationally representative sample of the U.S. population that reported similar rates of PTSD (3.4\%) and CPTSD (3.8\%; Cloitre et al., in press). It is probable that the trauma-exposed inclusion criteria used in this study selected for more distressed members of the general population. Consequently, while prior studies suggest that PTSD may be as or more common than CPTSD in the general population, the current findings suggest that CPTSD may be the more common diagnosis among members of the general population that are trauma-exposed. This is an important discovery given $70 \%$ of the world's population has experienced at least one traumatic life event (Benjet et al., 2016).

Our findings regarding the risk factors for PTSD and CPTSD are generally consistent with much of the theoretical and empirical psychotrauma literature. In the current study, females were twice as likely as males to experience PTSD and this aligns with a substantial body of evidence relating to DSM-based models of PTSD (Tolin \& Foa, 2006). Such differences have been predominantly attributed to biological factors (e.g., hormonal factors; Kajantie \& Phillips, 2006). The same applies for the observed association between less time having passed since traumatic exposure and the increased risk for PTSD. This association has been explained in terms of increased amygdala activity in the aftermath of traumatic exposure and thus an increased risk for fear-based responses (Ganzel, Casey, Glover, Voss, \& Temple, 2007).

Consistent with theoretical models of CPTSD (Cloitre, Garvert, Brewin, Bryant, \& Maercker, 2013), and findings from clinical (Hyland et al., 2018; Karatzias et al., 2017) and general population (Cloitre et al., in press) samples, we showed that interpersonal trauma is an independent risk factor for CPTSD. Interpersonal trauma exposure, particularly in childhood, tends to be more toxic with regard to its effects on health and well-being predominantly because it compromises a child's ability to successfully master certain developmental tasks (e.g., affect regulation, secure attachments; Cicchetti \& Toth, 1995). Interpersonal trauma also compromises the development of neurobiological systems involved in regulating arousal, emotion, stress responses, and reward processing (McLaughlin, Fox, Zeanah, \& Nelson, 2011), which are all related to the development of traumatic stress. Current findings are also in-line with the broader scientific literature, which indicates that urban dwelling increases the risk of multiple forms of psychiatric diagnoses, particularly those characterized by anxiety and mood problems (Peen, Schoevers, Beekam, \& Dekker, 2010). Possible explanations for this effect include differences in social support, stressful life events, and familial liability (Peen \& Dekker, 2004).

\subsection{Strengths and limitations of the study}

A notable strength of the current study is that it is the first to empirically assess the risk factors and comorbidities associated with the ICD-11 diagnoses of PTSD and CPTSD in a community sample of trauma-exposed adults. Nonetheless, there were several limitations. The community sample was drawn from a nationally representative panel, however, it cannot be ensured that the trauma-exposed participant sample itself was nationally representative, especially considering the high levels of comorbidities reported. Second, diagnoses were based on self-report measures rather than clinician-administered interviews and should, therefore, be interpreted cautiously. Third, the current study did not include children or adolescents, therefore, it is unknown if the current findings are relevant for younger persons exposed to trauma. However, it is important to highlight that many reported exposure to trauma as a younger person. Finally, the sample in the present study was the same as in Cloitre et al. (2018), although in the study by Cloitre et al. (2018), a more extended version of the ITQ was used.

\subsection{Implications for clinicians and future research}

Clinicians should be acutely aware of the symptom profiles of ICD-11 PTSD and CPTSD, and consider a diagnosis of CPTSD to be especially pertinent in cases where there is a history of interpersonal trauma (in childhood or in adulthood). It is critical that clinicians are cognizant of, and accurately diagnose, CPTSD, given that it is (a) so highly comorbid with a range of life-threatening conditions, and (b) may require enhanced interventions distinct from those currently offered for PTSD (Karatzias, Shevlin, et al., 2018). Work is ongoing to test the 
efficacy and acceptability of specific clinical interventions for CPTSD (Karatzias, Shevlin, et al., 2018) however, accurate recognition of CPTSD in general practice, and referral for appropriate interventions will facilitate recovery from the deleterious effects of CPTSD.

\section{CONFLICT OF INTERESTS}

Marylène Cloitre participated as a member of the World Health Organization Working Group on the Classification of Disorders Specifically Associated with Stress, reporting to the International Advisory Group for the Revision of ICD-10 Mental and Behavioural Disorders. However, the views expressed reflect the opinions of the authors and not necessarily the Working group or Advisory group and the content of this article does not represent WHO policy.

\section{AUTHOR CONTRIBUTIONS}

Thanos Karatzias and Philip Hyland conceptualized the manuscript. Mark Shevlin, Philip Hyland, and Aoife Bradley conducted the statistical analysis and wrote the first draft of the manuscript. All authors contributed to and have approved the final manuscript.

\section{DATA AVAILABILITY}

The data that support the findings of this study are available on request from the corresponding author. The data are not publicly available due to privacy or ethical restrictions.

\section{ORCID}

Thanos Karatzias (D) http://orcid.org/0000-0002-3002-0630

\section{REFERENCES}

American Psychiatric Association (2013). Diagnostic and Statistical Manual of Mental Disorders (5th ed). Washington, DC: American Psychiatric Press.

Ben-Ezra, M., Karatzias, T., Hyland, P., Brewin, C. R., Cloitre, M., Bisson, J. I., ... Shevlin, M. (2018). Posttraumatic stress disorder (PTSD) and Complex PTSD (CPTSD) as per ICD-11 proposals: A population study in Israel. Depression and Anxiety, 35, 264-274. https://doi.org/10. 1002/da.22723

Benjet, C., Bromet, E., Karam, E. G., Kessler, R. C., McLaughlin, K. A., Ruscio, A. M., ... Koenen, K. C. (2016). The epidemiology of traumatic event exposure worldwide: Results from the World Mental Health Survey Consortium. Psychological Medicine, 46, 327-343. https://doi. org/10.1017/S0033291715001981

Bradley, K. A., Bush, K. R., Epler, A. J., Dobie, D. J., Davis, T. M., Sporleder, J. L., ... Kivlahan, D. R. (2003). Two brief alcohol-screening tests from the Alcohol Use Disorders Identification Test (AUDIT): Validation in a female Veterans Affairs patient population. Archives of Internal Medicine, 163(7), 821-829. https://doi.org/10.1001/archinte.163.7. 821

Brewin, C. R., Cloitre, M., Hyland, P., Shevlin, M., Maercker, A., Bryant, R. A., ... Reed, G. M. (2017). A review of current evidence regarding the ICD-11 proposals for diagnosing PTSD and complex PTSD. Clinical
Psychology Review, 58, 1-15. https://doi.org/10.1016/j.cpr.2017.09. 001

Charlson, M., Pompei, P., Ales, K., \& MacKenzie, C. (1987). A new method of classifying prognostic comorbidity in longitudinal studies: Development and validation. Journal of Chronic Diseases, 40(5), 373-383.

Cicchetti, D., \& Toth, S. L. (1995). A developmental psychopathology perspective on child abuse and neglect. Journal of the American Academy of Child and Adolescent Psychiatry, 34(5), 541-565. https:// doi.org/10.1097/00004583-199505000-00008

Cloitre, M., Garvert, D. W., Brewin, C. R., Bryant, R. A., \& Maercker, A. (2013). Evidence for proposed ICD-11 PTSD and complex PTSD: A latent profile analysis. European Journal of Psychotraumatology, 4, 20706. https://doi.org/10.3402/ejpt.v4i0.20706

Cloitre, M., Hyland, P., Bisson, J. I., Brewin, C. R., Roberts, N. P., Karatzias, T., \& Shevlin, M. (in press). ICD-11 PTSD and Complex PTSD in the United States: A population-based study. Journal of Traumatic Stress.

Cloitre, M., Shevlin, M., Brewin, C. R., Bisson, J. I., Roberts, N. P., Maercker, A., ... Hyland, P. (2018). The International Trauma Questionnaire: Development of a self- report measure of ICD-11 PTSD and complex PTSD. Acta Psychiatrica Scandinavica, 138, 536-546. https://doi.org/ 10.1111/acps.12956

Dawson, D. A., Smith, S. M., Saha, T. D., Rubinsky, A. D., \& Grant, B. F. (2012). Comparative performance of the AUDIT-C in screening for DSM-IV and DSM-5 alcohol use disorders. Drug and Alcohol Dependence, 126(3), 384-388. https://doi.org/10.1016/j.drugalcdep. 2012.05.029

Ehring, T., \& Quack, D. (2010). Emotion regulation difficulties in trauma survivors: The role of trauma type and PTSD symptom severity. Behavior Therapy, 41(4), 587-598. https://doi.org/10.1016/j.beth.2010. 04.004

Ganzel, B., Casey, B. J., Glover, G., Voss, H. U., \& Temple, E. (2007). The aftermath of 9/11: Effect of intensity and recency of trauma on outcome. Emotion, 7(2), 227-238. https://doi.org/10.1037/15283542.7.2.227

Hyland, P., Murphy, J., Shevlin, M., Vallières, F., McElroy, E., Elklit, A., ... Cloitre, M. (2017). Variation in post-traumatic response: The role of trauma type in predicting ICD-11 PTSD and CPTSD symptoms. Social Psychiatry and Psychiatric Epidemiology, 52(6), 727-736. https://doi. org/10.1007/s00127-017-1350-8

Hyland, P., Shevlin, M., Fyvie, C., \& Karatzias, T. (2018). Posttraumatic stress disorder and complex posttraumatic stress disorder in DSM-5 and ICD-11: Clinical and behavioral Correlates. Journal of Traumatic Stress, 31(2), 174-180. https://doi.org/10.1002/jts.22272

Kajantie, E., \& Phillips, D. I. (2006). The effects of sex and hormonal status on the physiological response to acute psychosocial stress. Psychoneuroendocrinology, 31(2), 151-178. https://doi.org/10.1016/j.psyneuen.2005. 07.002

Karatzias, T., Cloitre, M., Maercker, A., Kazlauskas, E., Shevlin, M., Hyland, P., ... Brewin, C. R. (2018). PTSD and Complex PTSD: ICD-11 updates on concept and measurement in the UK, USA, Germany and Lithuania. European Journal of Psychotraumatology, 8(sup7), 1418103. https://doi. org/10.1080/20008198.2017.1418103

Karatzias, T., Shevlin, M., Fyvie, C., Hyland, P., Efthymiadou, E., Wilson, D., ... Cloitre, M. (2017). Evidence of distinct profiles of posttraumatic stress disorder (PTSD) and complex posttraumatic stress disorder (CPTSD) based on the new ICD-11 Trauma Questionnaire (ICD-TQ). Journal of Affective Disorders, 207, 181-187. https://doi.org/10.1016/j. jad.2016.09.032

Karatzias, T., Shevlin, M., Hyland, P., Brewin, C. R., Cloitre, M., Bradley, A., ... Roberts, N. P. (2018). The role of negative cognitions, emotion regulation strategies, and attachment style in complex post-traumatic stress disorder: Implications for new and existing therapies. British Journal of Clinical Psychology, 57(2), 177-185. https://doi.org/10.1111/ bjc. 12172 
Keeley, J. W., Reed, G. M., Roberts, M. C., Evans, S. C., Robles, R., Matsumoto, C., ... Maercker, A. (2016). Disorders specifically associated with stress: A case-controlled field study for ICD-11 mental and behavioural disorders. International Journal of Clinical and Health Psychology, 16(2), 109-127. https://doi.org/10.1016/j.ijchp.2015.09.002

Kelly, T. M., Donovan, J. E., Chung, T., Bukstein, O. G., \& Cornelius, J. R. (2009). Brief screens for detecting alcohol use disorder among 18-20 year old young adults in emergency departments: Comparing AUDITC, CRAFFT, RAPS4-QF, FAST, RUFT-Cut, and DSM-IV 2-Item Scale. Addictive Behaviors, 34(8), 668-674. https://doi.org/10.1016/j.addbeh. 2009.03.038

Kertz, S., Bigda-Peyton, J., \& Bjorgvinsson, T. (2013). Validity of the generalized anxiety disorder-7 scale in an acute psychiatric sample. Clinical Psychology and Psychotherapy, 20(5), 456-464. https://doi.org/10.1002/cpp.1802

Kroenke, K., Spitzer, R. L., \& Williams, J. B. W. (2001). The PHQ-9: Validity of a brief depression severity measure. Journal of General Internal Medicine, 16(9), 606-613. https://doi.org/10.1046/j.1525-1497.2001. 016009606.x

Kroenke, K., Strine, T. W., Spitzer, R. L., Williams, J. B. W., Berry, J. T., \& Mokdad, A. H. (2009). The PHQ- 8 as a measure of current depression in the general population. Journal of Affective Disorders, 114(1-3), 163-173. https://doi.org/10.1016/j.jad.2008.06.026

Maercker, A., Brewin, C., Bryant, R., Cloitre, M., Reed, G., vanOmmeren, M., ... Saxena, S. (2013). Proposals for mental disorders specifically associated with stress in the ICD-11. Lancet, 381. https://doi.org/10. 1016/S0140-6736(12)62191-6

Manea, L., Gilbody, S., \& McMillan, D. (2015). A diagnostic meta-analysis of the Patient Health Questionnaire-9 (PHQ-9) algorithm scoring method as a screen for depression. General Hospital Psychiatry, 37(1), 67-75. https://doi.org/10.1016/j.genhosppsych.2014.09.009

McLaughlin, K. A., Fox, N. A., Zeanah, C. H., \& Nelson, C. A. (2011). Adverse rearing environments and neural development in children: The development of frontal electroencephalogram asymmetry. Biological Psychiatry, 70(11), 1008-1015. https://doi.org/10.1016/j.biopsych.2011.08.006

Nayak, M. B., Bond, J. C., Cherpitel, C., Patel, V., \& Greenfield, T. K. (2009). Detecting alcohol-related problems in developing countries: $A$ comparison of 2 screening measures in India. Alcoholism, Clinical and Experimental Research, 33(12), 2057-2066.

Peen, J., \& Dekker, J. (2004). Is urbanicity an environmental risk-factor for psychiatric disorders? Lancet, 363(9426), 2012-2013. https://doi.org/ 10.1016/S0140-6736(04)16486-6
Peen, J., Schoevers, R. A., Beekam, A. T., \& Dekker, J. (2010). The current status of urban-rural differences in psychiatric disorders. Acta Psychiatrica Scandinavica, 121, 84-93. https://doi.org/10.1111/j.1600-0447.2009. 01438.x

Saunders, J. B., Aasland, O. G., Babor, T. F., \& de laFuente, J. R. (1993). Development of the Alcohol Use Disorders Identification Test (AUDIT): WHO collaborative project on early detection of persons with harmful alcohol consumption: II. Addiction, 88(6), 791-804. https://doi.org/10.1111/j.1360-0443.1993.tb02093.x

Shevlin, M., Hyland, P., Vallieres, F., Bisson, J., Makhashvili, N., Javakhishvili, ...Roberts, B. (2018). A comparison of DSM-5 and ICD11 posttraumatic stress disorder rates and comorbidity: An analysis of the Ukrainian Internally Displaced Person's Mental Health Survey. Acta Psychiatrica Scandinavica, 137, 138-147. https://doi.org/10.1111/ acps. $12840(\mathrm{IF}=4.984)$

Spitzer, R., Kroenke, K., Williams, J., \& Löwe, B. (2006). A brief measure for assessing generalized anxiety disorder-the GAD-7. Archives of Internal Medicine, 166(10), 1092-1097. https://doi.org/10.1001/ archinte.166.10.1092

Tolin, D. F., \& Foa, E. B. (2006). Sex differences in trauma and posttraumatic stress disorder: A quantitative review of 25 years of research. Psychological Bulletin, 132(6), 959-992. https://doi.org/10. 1037/0033-2909.132.6.95

Weathers, F., Blake, D. D., Schnurr, P. P., Kaloupek, D. G., Marx, B. P., \& Keane, T. M. (2013). The Life Events Checklist for DSM-5 (LEC-5). National Center for PTSD, 5(October), Instrument available from the National Center for PTSD at www.ptsd.va.gov

World Health Organization. (2018). International statistical classification of diseases and related health problems (11th Revision). Retrieved February 11, 2019 from https://icd.who.int/browse11//-m/en

How to cite this article: Karatzias T, Hyland P, Bradley A, et al. Risk factors and comorbidity of ICD-11 PTSD and complex PTSD: Findings from a trauma-exposed population based sample of adults in the United Kingdom. Depress Anxiety. 2019;1-8. https://doi.org/10.1002/da.22934 